\title{
Tularaemia: A Re-Emerging Infectious Zoonotic Disease of Public Health Significance
}

\author{
Mahendra Pal $^{1, *}$, Margo Yonas Shuramo ${ }^{2}$, Kirubel Paulos Gutama ${ }^{3}$ \\ ${ }^{1}$ Narayan Consultancy on Veterinary Public Health and Microbiology, Anand, India. \\ ${ }^{2}$ Dagam Woreda Livestock and Fishery Resource Development Office, North Shoa, Ethiopia. \\ ${ }^{3}$ Adaba Woreda Livestock and Fishery Resource Development Office, West Arsi, Ethiopia.
}

How to cite this paper: Mahendra Pal, Margo Yonas Shuramo, Kirubel Paulos Gutama. (2022) Tularaemia: A Re-Emerging Infectious Zoonotic Disease of Public Health Significance. International Journal of Clinical and Experimental Medicine Research, 6(1), 48-51.

DOI: 10.26855/ijcemr.2022.01.009

Received: November 22, 2021

Accepted: December 13, 2021

Published: December 23, 2021

*Corresponding author: Mahendra Pal, Narayan Consultancy on Veterinary Public Health and Microbiology, Anand, India.

Email: palmahendra2@gmail.com

\begin{abstract}
Tularemia is a re-emerging bacterial disease that affects humans, wild animals, and domestic animals. The disease is caused by Francisella tularensis that is found all over the world, but it is most commonly reported in North America, a few Scandinavian and Asian countries. The disease can occur in sporadic and epidemic form. Humans acquire the infection through the handling or ingestion of infected animals, vector bites, interaction with the aquatic environment, and aerosol inhalation. The disease classically manifests by the ulceroglandular, glandular, oculoglandular, oropharyngeal, respiratory and typhoidal forms. A rapid onset of fever, chills, headaches, diarrhea, muscular aches, joint pain, dry cough, and increasing weakening are all common symptoms. Because of its low infectious dose, ability to survive in the environment, and ability to be easily disseminated by aerosol, Francisella tularensis has been designated as a "category A" agent of greatest concern for bioterrorism. Laboratory help that include microbiological, immunological and molecular techniques is needed to make an unequivocal diagnosis of disease. In untreated patients, the fatality may be high. Tularemia can be prevented by using insect repellent, wearing gloves when handling sick or dead animals, thoroughly cooking game meat before eating it and not drinking untreated water. Prophylactic treatment and health education of the high risk groups is imperative.
\end{abstract}

\section{Keywords}

Animals, Humans, Francisella tularensis, Public Health, Prevention, Tularemia

\section{Introduction}

Tularemia is a highly virulent disease that is caused by Francisella tularensis, a small, acute, febrile, granulomatous, pleomorphic, zoonotic bacterial pathogen [1]. Small mammals, such as rabbits, rats, and hares, as well as the insects that feed on them (hence the disease's alternate names of rabbit fever and deerfly fever), are important sources of human infection [2]. Tularemia case clusters in humans are often preceded by outbreaks in wildlife and detection of the pathogen in captured animals [3].

Francisella infection can cause infection from asymptomatic illness to septic shock and death, depending on the severity of the infecting strain, the portal of entry, the inoculums, and the host's immunological status. F. tularensis sub spp. tularensis (type A) and F. tularensis sub spp. holarctica (type B) are the two subspecies of Francisella tularensis that cause the majority of human infections [4]. This microbe is classified as a category ' $\mathrm{A}$ ' potential bio- 
logical concern because it is highly contagious and can be disseminated by aerosols [5]. Therefore, the objective of this paper is to review tularaemia and its public health importance.

\section{Aetiology}

Francisella tularensis is a Gram-negative pleomorphic, nonmotile, aerobic, intracellular, coccobacillus, and non-spore-forming bacteria that cause tularaemia [6]. Francisella tularensis is in the genus Francisella, the family Francisellaceae [7]. Subspp. tularensis (also known as biovar type A), subspp. palaearctica (also known as biovar type B or holarctica), mediasiatica, and novicida are the four subspecies of Francisella tularensis. Human disease is strongly linked to Type A and Type B biovars [8]. Francisella tularensis may survive in water, mud, and animal carcasses for lengthy periods of time. In frozen meat, the organism can live for years. It can be killed by moist heat $\left(121^{\circ} \mathrm{C}\right.$ for 15 minutes) or dry heat $\left(160^{\circ}-170^{\circ} \mathrm{C}\right.$ for at least 1 hour) as well as $1 \%$ hypochlorite, $70 \%$ ethanol, glutaraldehyde, or formaldehyde [9].

\section{Epidemiology}

Tularaemia is a re-emerging bacterial zoonosis of public health concern and can occur in sporadic as well as in epidemic form [6]. Francisella tularensis can infect humans and a wide range of animals, including more than 100 species of wild and domestic mammals, 25 species of birds, and several species of amphibians and reptiles. The infection has been diagnosed in beaver, bird, cat, cattle, deer, dog, fish, fox, horse, horse, mink, muskrat, pig, rabbit, sheep, and wild rodents [10,11]. It is most commonly found in North America, several Scandinavian countries, and a few Asian countries [11]. People can contract Francisella tularensis infection by vector-borne transmission; and contact with an infected animal carcass (most commonly wild rabbits) that can cause the ulceroglandular form of the disease. Although the organism can enter unbroken skin, minor skin lesions in the host are likely to aid in the organism's penetration. The ulceroglandular type of the disease can also be caused by contact with infected fluids on the mucous membranes of the host. Oropharyngeal or typhoidal tularemia can be caused by ingesting infected meat or water. Tularemia can also be contracted by inhaling infected material that has been aerosolized, however, person-to-person transmission is rare or non-existent [12]. Infection can also be acquired by accidental bites of animals, such as dog, shunk, and cat whose mouths are contaminated from eating diseased lagomorphs [10]. Veterinarians, farmers, foresters, hunters, and wildlife specialists are at high risk because ticks, mosquitos (Aedes, Culex, and Anopheles), and diseased animals are more likely to come into contact with them [13].

\section{Clinical Spectrum}

\subsection{Humans}

Tularemia symptoms differ depending on where the organism enters the body [14]. Fever, chills, anorexia, and malaise are the first nonspecific symptoms that appear three to five days (range 1 to 21 days) after exposure. Headache, fatigue, soreness in the chest or muscles, abdominal pain, emesis, or diarrhoea is some of the other symptoms [1]. The disease classically manifests by six clinical forms, the ulceroglandular, glandular, oculoglandular, oropharyngeal, respiratory and typhoidal forms. The most frequent kind of tularaemia, ulceroglandular tularaemia, begins with an ulcer forming at an inoculation site, generally where the person was bitten by an insect or animal. The organisms then travel from the inoculation site to regional lymph nodes, which swell and become painful; fever, chills, headache, and lethargy follow. The next most prevalent form of tularemia is typhoidal or septicaemic tularemia, which is spread through ingestion and manifests as pneumonia, fever, chills, myalgia, lethargy, and weight loss. The glandular type (no ulcer forms), oculoglandular form (Francisella tularensis enters through the eye), oropharyngeal form (from consuming undercooked contaminated meat, generally rabbit), and respiratory form (Francisella tularensis is inhaled) are the other forms that are far more infrequent [15].

\subsection{Animals}

The natural infection has been diagnosed in beaver, bird, cat, cattle, deer, dog, fish, fox, horse, horse, mink, muskrat, pig, rabbit, sheep, and wild rodents [10]. Tularemia type A is highly pathogenic, causing death in cats and nonhuman primates. Sheep and cats might be infected without showing symptoms, or they can develop bacteremia, fever, and respiratory infection. Cats may get ulceroglandular or oropharyngeal infection as a result of contact with contaminated prey. Increased pulse and respiratory rates, coughing, diarrhea, oral ulceration, pollakiuria with lymphadenopathy, and hepatosplenomegaly are some of the clinical symptoms. Untreated outbreaks in lambs can result 
in up to $15 \%$ mortality [16].

\section{Diagnosis}

The causative agent of tularaemia Francisella tularensis is a biohazardous pathogen. Therefore, the culture and diagnosis of tularemia require highly equipped laboratories and skilled laboratory personnel. Bacterial isolation should take place in Biosafety level 3 laboratories [16].

Tularemia is diagnosed primarily through positive serology in conjunction with clinical and epidemiological settings. The isolation of pathogen can be attempted from clinical specimens, such as sputum, and aspirates from lymph nodes on glucose cysteine blood agar/cysteine heart agar [10]. Bacterial colonies appear on solid culture media within 2-3 days of incubation at $37^{\circ} \mathrm{C}$, and preliminary confirmation can be obtained easily and quickly by agglutination of the bacteria in immune serum. Serum antibodies (IgM or IgG antibodies) against Francisella tularensis can be detected using a microagglutination test or an ELISA method [10]. Cross-reactivity with Salmonella, Brucella, Legionella, and Yersinia species has been documented [17]. It is important to mention that fluorescent antibody test (FAT) helps in early identification of the agent [10]. When tissue samples are available, polymerase chain reaction (PCR)-based procedures are useful. MALDI-ToF mass spectrometry, a new technique, has recently been evaluated as a useful tool for quickly identifying and typing isolated Francisella tularensis strains [6].

\section{Tularaemia for Bioterrorism}

Because it can cause an incapacitating and sometimes deadly infection, Francisella tularensis is classed as a high-risk, Category "A" potential bioterrorism agent. When the bacterium is inhaled, it causes severe respiratory and systemic illness with a $30 \%$ or higher fatality rate if not treated with antibiotics. It is highly contagious and easily distributed in an aerosol form, despite the fact that creating this form of the bacteria takes complex technology. It is abundantly found in nature, therefore obtaining the bacterium and growing it under simple laboratory settings would not be difficult. There is presently no vaccination available, and an outbreak might place a significant burden on the public health [18].

\section{Treatment, Prevention and Control}

People who have been exposed to or afflicted with tularemia should start taking antibiotics right away. Tetracyclines, fluoroquinolones, and aminoglycosides are all effective therapies, and doxycycline or a fluoroquinolone can be administered as a prophylactic medication following a high-risk exposure [12]. Individuals can readily protect themselves by adopting precautions to reduce their risk of infection, such as not drinking, bathing, swimming, or working in untreated water where infection may be frequent among wild animals. When skinning, handling, or dressing wild animals, especially rabbits, wear impermeable gloves and clothing, wild rabbit and rodent meat should be fully cooked. Insect repellents should be used. Certain professional group, such as farmers, gardeners, and rice field workers should wear protective masks against infected dust and aerosols. Do not get bitten by deer flies or ticks. It is necessary to check to see if the area around the house is tick-friendly. Keep the grass mowed and weeds trimmed, and anyone who comes into close contact with rabbits or other suspected animals should get prophylactic treatment against the pathogen $[6,10,19]$. In addition, it is important to educate the public to avoid bites of ticks and other arthropods when working in tularaemia endemic area [10].

\section{Conclusion}

Tularemia is a bacterial zoonosis caused by Francisella tularensis, which has the potential to trigger bioterrorism. Insect or tick bites, direct contact with a contaminated environment (mud or water), diseased animals, or swallowing undercooked meat or inhaling contaminated dust are the most common methods of transmission to other animals or people (hay or soil). People who are at risk of infection can get prophylactic antibiotics to prevent disease, as currently, there is no safe, potent, authorized vaccine available in the market. It is emphasised that sincere attempts should be directed to develop a safe, potent and cheap vaccine that may be affordable even by the low resource nations of the world.

\section{Acknowledgements}

We are very grateful to Prof. Dr. R.K. Narayan for critically reading our manuscript. This paper is dedicated to the scientists who contributed in the field of tularaemia. 


\section{References}

[1] Auwaerter, P. G., Penn, R. L. (2015). Francisella tularensis (Tularemia). In: Mandell, Douglas, and Bennett’s Principles and Practice of Infectious Diseases. 9th ed., Bennet JE, Dolin R, Blaser MJ (Eds.), Elsevier, Philadelphia.

[2] Faber, M., Heuner, K., Jacob, D., and Grunow, R. (2018). Tularemia in Germany-A re-emerging zoonosis. Frontiers in cellular and infection microbiology, 8, 40.

[3] Splettstoesser, W. D., Tomaso, H., Al Dahouk, S., Neubauer, H. and Schuff-Werner. P. (2005). Diagnostic procedures in tularaemia with special focus on molecular and immunological techniques. Journal of Veterinary Medicine, 52, $249-261$.

[4] Johansson, A., Larkeryd, A., Widerstrom, M. (2014). An outbreak of respiratory tularemia caused by diverse clones of Francisella tularensis. Clinical and Infectious Disease, 59, 1546-53.

[5] Hestvik, G., Warns-Petit, E., Smith, L. A., Fox, N. J., Uhlhorn, H., Artois, M., Hannant, D., Hutchings, M. R., Mattsson, R., and Yon, L. (2015). The status of tularemia in Europe in a one-health context: a review. Epidemiology and Infection, 143, 2137-60.

[6] Derya, K. Y, Buyuk, F., Ashraf, A., and Salah, M. (2021). Tularemia: a re-emerging tick-borne infectious disease. Folia Microbiologica, 66, 1-14.

[7] Sjostedt, A. (2005). Francisella. In: Garrity G et al., eds. The Proteobacteria, Part B, Bergey’s Manual of Systematic Bacteriology, New York, NY, Springer, 200-210.

[8] Kilic, S. and Yesilyurt, M. (2011). Tularemia: A general overview on current treatment options. Klimik Journal, $24,2-10$.

[9] Hennebiquea, A., Boisset, S., Maurin, M. (2019). Tularemia as a waterborne disease: a review. Emerging Microbes and Infection, 8, 1027-1042.

[10] Pal, M. (2007). Zoonoses. Second Edition. Satyam Publishers, Jaipur, India.

[11] Stefanie, S., Anja, S., Erwin, H., Gunter, W., and Rosa, W. (2020). Tularemia goes West: Epidemiology of an emerging infection in Austria. Microorganism, 8, 1597.

[12] Dennis, D. T., Inglesby, T. V., Henderson, D. A., Bartlett, J., Ascher, M., Ejtzen, E., Fine, A., Friedlander, A., Hauer, K., Layton, M., Lillibridge, S., McDade, J., Osterholm, M., O’Toole, G., Parker, G., Perl, T., Russell, P. and Tonat, K. (2001). Tularemia as a biological weapon: medical and public health management. Journal of American Medical Association, 285, 2763-2773.

[13] Foley, J. E. and Nieto, N. C. (2010). Tularemia. Veterinary Microbiology, 27, 332-8.

[14] Byington, C. L., Bender, J. M., Ampofo, K., Pavia, A. T., Korgenski, K., Daly, J., Christenson J. C., and Adderson E. (2008).Tularemia with vesicular skin lesions may be mistaken for infection with herpes viruses. Clinical and Infectious Disease, 47, 4-6.

[15] Saber, E., Mahdi, R., Ahmad, G., Mohammed, M. G., Simin, K., Ahmad, M., Hossein, A. C., Anders, J., Max, M., and Ehsan, M. (2021). Francisella tularensis human infections in a village of northwest Iran. BMC Infectious Disease, 21,310.

[16] American Society for Microbiology (ASM). (2016). Sentinel level clinical laboratory guidelines for suspected agents of bioterrorism and emerging infectious diseases: Francisella tularensis. https://www.asm.org/ images/PSAB/LRN/Tularemia.

[17] Buyuk, F., Çelebi, O., Çelik, E., Çelebi, B., Kiliç, S., Gulmez Saglam, A., Şahin, M. (2016). The prevalence of tularemia in occupational groups that have contact with animals. Turkish Journal of Medical Science, 46, 451-456.

[18] Adalja, A. A., Toner, E., and Inglesby, T. V. (2015). Clinical management of potential bioterrorism-related conditions. New England Journal of Medicine, 372, 954-62.

[19] World Health Organization (WHO). (2007). Guidelines on Tularaemia. Geneva, Swizerland. 